\title{
In vitro assessment of solubility and bioavailability of vinblastine using nanoparticulated formulations
}

\author{
ALOK SINGH, MANAR W. JAN AND JISHNU NASKAR*
}

Department of Molecular and Cellular Engineering, Sam Higginbottom Institute of Agriculture, Technology and Sciences, ALLAHABAD (U.P.) INDIA

\section{ARITCLE INFO}

Received : 21.01 .2016

Revised : 27.02 .2016

Accepted : 08.03 .2016

KEY WORDS :

Catharanthus roseus, Terpenoid indole alkaloid, Vinblastine, Silver

Nanoparticles, LDH, MMT
*Corresponding author:

Email: jishnu.naskar@ shiats.edu.in

\begin{abstract}
Catharanthus roseus (Madagascar periwinkle) is an ornamental plant belonging to the Apocynaceae family. Besides its importance as an ornamental plant, its interest today is centered on its capacity to biosynthesize a great variety of terpenoid indole alkaloids (TIAs) which are valued highly due to their wide spectrum of pharmaceutical application. Among these, vinblastine and vincristine are of particular importance because of their wide use in cancer chemotherapy. Vinblastine can have extensive use for the treatment of lung cancer, breast cancer, head and neck cancer, and testicular cancer. It is also used to treat Langerhens cell histocytosis. This study was done to assess the solubility of vinblastine. The extracted crude vinblastine was encapsulated with nanoparticles and solubility was determined at different $\mathrm{pH}$ range.Silver Nanoparticles was synthesized using reduction method, LDH was synthesized by Co-precipitation method while MMT was purchased from Sigma-Aldrich.Silver NP formulation showed maximum solubility at $\mathrm{pH} 10.4$ and least at $\mathrm{pH}$ 6. In case of Layered Double Hydroxide (LDH) Nanoparticles and Montmorillonite nanoparticles (MMT) maximum solubility was obtained at $\mathrm{pH} 7$ and $\mathrm{pH} 8.6$, respectively. The increased solubility range of the drug with various nanoparticles formulation will enhance the bioavailability of the drug at physiological pH.This study shows that formulation of NP-TIA's has significant potential in the field of chemotherapy and drug delivery.
\end{abstract}

How to view point the article : Singh, Alok, Jan, Manar W. and Naskar, Jishnu (2016). In vitro assessment of solubility and bioavailability of vinblastine using nanoparticulated formulations. Internat. J. Plant Protec., 9(1) : 199-203. 